\title{
VIEWPOINT Developing open access in conservation research
}

\author{
Wanhong Yang
}

C onservation research can be broadly defined as the applied research on conservation of ecosystems, which ranges from biological conservation and water resources protection to climate change mitigation. In recent decades, relevant disciplinary fields, including conservation biology, landscape ecology, soil science, and water resources engineering, have developed to address complex conservation issues, with additions from interdisciplinary and/or transdisciplinary research (Reyers et al. 2010). Furthermore, multiagency conservation research programs have been established in recent years to build the bridge between conservation research and decision making, such as the Natural Capital Project jointly developed by Stanford University, The Nature Conservancy, and World Wildlife Fund (Tallis et al. 2010); the Market Based Instrument (MBI) Program in Australia (Grafton 2005); the Conservation Effect Assessment Project (CEAP) in the United States (Duriancik et al. 2008); and the Watershed Evaluation of Beneficial Management Practices (WEBs) Project in Canada (Yang et al.2007). In the process, communication and collaboration have played a significant role in facilitating conservation research development. However, the flow of information within and between conservation research projects, groups, and agencies may be still not as free as it should be. Data sharing is still restricted to certain extent due to institutional and other barriers (Nelson 2009). The source codes of some models and tools are not open to the users. Some of the information or products may be open, but lack of clear documentation still causes access difficulties to the users. With increasing demand on conservation knowledge development, improving the sharing of information and products has the potential to significantly increase

Wanhong Yang is associate professor in the Department of Geography, University of Guelph, Guelph, Ontario, Canada. He is also an associate editor and member of editorial board for the Journal of Soil and Water Conservation. the productivity of conservation research. Therefore, a critical question arises, can we move forward to develop "open access" in conservation research?

\section{THE DEFINITION OF OPEN ACCESS}

Open access originated from initiatives for promoting free access of published journal articles in order to maximize the benefits of scientific development (Velterop 2003). Open access has been increasingly endorsed by scientific funding agencies, research institutions, and researchers. The Directory of Open Access Journals as a portal has had more than 5,000 journals in its directory.

In this article, I would like to extend the definition of open access for discussion and debate. Open access is the process where receivers openly obtain information and products from providers. Open access also implies open source. As an ultimate goal, open access in conservation research involves all information, all researchers and institutions, and the general public. Open access is gradually developing in conservation research communities. For example, Conservation Commons Initiative (http:// conservationcommons.net) and Global Biodiversity Information Facility (http:// www.gbif.org) have been established to promote open access of published papers, working papers, data, and other products. However, open access needs to be developed extensively in conservation research communities. Realistically, open information sharing can start from researchers and groups within a project, between collaborative projects, and then extend beyond. Information and products for open sharing can range from published or finalized products to intermediate products. Sharing agreements can be initially developed between involved parties and then evolve to open access agreements, licenses, or policies. Open sharing services can be provided by individual researchers or institutions in early stages and then developed into a combination of individual and thirdparty providers such as central repositories. Likely, full open access can not be achieved due to legal, confidentiality, cost, and other restrictions, but moving forward along the open access continuum is important.

Open access can cover the full spectrum of information resided in conservation research. Generally speaking, there are four categories of information and products potentially suitable for open access: data and data methodology, models and software, modeling methodology, and modeling outputs.

Publicly available data such as geospatial and monitoring data products have been important sources for conservation research. In addition, extensive data collection and monitoring have also been conducted within research groups and institutions. Data sharing has been happening in conservation research communities. For example, ecological data sharing has been developing in large initiatives such as the National Ecological Observatory Network (NEON) (Parr and Cummings 2005; Pullin and Salafsky 2010). While conservation data sharing needs to be further developed, the exchange of data methodology is also equally important. For example, information sharing on Best Management Practices (BMP) experiments has the potential to benefit other existing or new initiatives. The methodology for BMP experiments may include BMP design and data collection methods such as sampling design and technology (Groffman et al. 2007).

Conservation research models and Geographic Information System (GIS)/ graphic interface software have a long history of development, and new models and interface software are continuing to be developed. Some of the important environmental models such as the Soil and Water Assessment Tool (SWAT) from USDA open source codes to the users (Gassman et al. 2010). However, the degree of open source code varies across models and software. Some models are open source but the GIS/graphic interfaces are not. Some models are open source with certain restrictions. Some models are open source, but limited documentation causes 
barriers to their use. Improving the source code "openness" of models and software still has a long way to go.

Model application is an important scholarly field with innovations. Model applications have important scientific contributions that can be openly shared with other researchers. Using SWAT modeling as an example, researchers need to make decisions on processing digital elevation model (DEM), soil, land use, and agricultural management data for model setup. Extensive expertise is required to develop a set of parameter values for model calibration and validation. If all applications of a specific model or a group of models can be clearly documented and openly shared, then the model strengths and limitations can be better understood. This will lead to improved model applications and new model developments for conservation research.

The open sharing of modeling outputs or research results seems to be a straightforward issue. However, it may not be the case in certain settings. For example, conservation auction studies revealed that sharing information on environmental benefit index (EBI) to bidders has an impact on bidding behavior and may lead to higher bid payment rates (Kirwin et al. 2005). This pattern has been observed in US Conservation Reserve Program (CRP) bidding process. The learning of EBI and payment pattern across sign-up periods could be one of the factors in driving up program costs (Claassen 2009). Therefore, the complication involved in open access of detailed and/or location-specific information on conservation outputs may need to be treated with caution.

\section{THE BENEFITS AND BARRIERS OF OPEN ACCESS}

The benefits of open access seem obvious. Literature has explained various benefits of open access such as cost savings and innovations (Lerner and Tirole 2001; Parr and Cummings 2005). In addition to these general benefits, I would like to justify three key benefits of open access that serve the mission of conservation research in general.

First, open access facilitates integrated conservation research. In addition to multi- disciplinary and transdisciplinary research in academia, conservation research programs such as the Natural Capital Project, MBI, CEAP, and WEBs have made significant efforts to develop integrated conservation research (Duriancik et al. 2008; Maresch et al. 2008; Turner and Daily 2008; Yang et al. 2007), but the difficulties could be significant as well. Integration requires efforts that include more than just linking inputs and outputs of various data and models. For integration, an important premise is that all data and modeling components are transparent. For example, the open source of SWAT and on-farm economic model provided a basis for spatial integration of hydrologic response units (HRUs) and farm field boundaries and also tight interaction of common model parameters such as soil properties, fertilizer rates, and management options. Open access makes different disciplines know each other and, therefore, facilitates integrated conservation research.

Second, open access has the potential to speed up the geographic coverage of conservation research. Data collection, model development, and modeling are costly efforts, which lead to undersupply of conservation assessment information for many geographic areas. Pilot studies in important and/or representative areas continue to be the strategy to develop conservation research (Lawler et al. 2006). With open access, spatial expansion of conservation research can utilize the benefits of resource savings, thereby supporting regional and national conservation studies.

Third, open access benefits conservation technology transfer. In conservation research, some of the data and models may need to be developed into user-friendly data products and management tools with GIS/graphic user interface. If open access can be developed for data, models, and software, the time and efforts in further development of these data products and tools can be considerably reduced. Consequently, conservation technology transfer can be accelerated. The open access development can greatly facilitate building technology support structure for conservation management and decision making.
Of course, the benefits of open access come with costs and related barriers. For some providers, cost recovery or profit making is the goal, so open access may not be the option. Even with open access, extra costs could be involved because of documentation and other efforts. Existing repositories may need to be adapted or new repositories need to be built for open access. The compatibility of open access with existing legal framework, including freedom of information, needs to be delicately developed. Particularly, intellectual property right protection for information and product providers is one of the core issues in developing open access. Attention also needs to be paid to access right and other rights of information and product receivers.

\section{THE STRATEGIES FOR DEVELOPING OPEN ACCESS}

Developing open access is likely to be a long-term process. Similar to conservation actions, adaptive management has the potential to facilitate the open access process in conservation research (Manale 2008; Grantham et al. 2010). As a starting point, extensive discussions on open access can be initiated within conservation research communities with a series of questions. For example, What open access means to you? What are your experiences with open access? How do you evaluate the benefits and costs of open access? What are the obstacles of open access? How to protect interests of researchers and/or providers during open access? How can we better promote open access? These discussions would be important for understanding common grounds and differences and also for identifying pitfalls.

In the discussion process, open access can be experimented within various collaborative projects and then gradually expanded to other projects. These experiments can provide a test bed for developing open access guidelines, including the rights and responsibilities of providers and receivers, and the standardized formats for documentation of data and data methodology, models and software, modeling, and modeling outputs. For example, citation requirements could be stipulated in using open access information and prod- 
ucts. Similar to metadata of geospatial data, open access documentation for modeling methodology may include names of researchers, contact information, funding agency, models and software used, input data statistics, model parameter set, calibration and validation results, output data statistics, and evaluation of modeling strengths and limitations. Draft open access guidelines can be circulated for extensive consultation and voluntary adoption. Conservation research programs can collaborate with professional organizations in engineering, soil science, ecology, environmental modeling and software, and other related disciplines to develop open access projects and documents. With continued improvements, open access guidelines can be finalized and developed into open access policy for implementation in conservation research communities.

\section{CONCLUSION}

Open access issues surrounding conservation research could be extensive. In this article, I intended to provide some preliminary thoughts and also raise questions for discussion and debate. Conservation research is now at an exciting time. We are developing conservation research from a wealth of historic conservation knowledge. We are also facing escalating demand from governments, nongovernmental organizations, private sectors, and the general public on evaluating conservation effects, planning conservation actions, and developing the ensuring science base. The new era of conservation research calls for a new paradigm and also collective wisdom on open access. Likely, open access will initially be a voluntary process. Open access guidelines can be available for adoption with proper measures to protect the intellectual property and other rights of information providers, including researchers and institutions. Open access policies can then be further developed and finalized for implementation as institutional arrangements. There is no doubt that numerous challenges are ahead in developing open access. However, open access has the potential to better serve the mission of conservation research in general. With the advantages outweighing disadvantages, we need to take actions now in order to harvest the benefits of open access for improving conservation research, management, and decision making.

\section{ACKNOWLEDGEMENTS}

The author would like to thank John Lindsay, associate professor, and Yongbo Liu, research scientist in the Department of Geography, University of Guelph, Guelph, Ontario, Canada, for their insightful comments.

\section{REFERENCES}

Claassen, R. 2009. Cost-effective conservation programs: The role of economics. Journal of Soil and Water Conservation 64(2):53A-54A.

Duriancik, L.F., D. Bucks, J.P. Dobrowolski, T. Drewes, S.D. Eckles, L. Jolley, R.L. Kellogg, D. Lund, J.R. Makuch, M.P. O'Neill, C.A. Rewa, M.R. Walbridge, R. Parry, and M.A. Weltz. 2008. The first five years of the Conservation Effects Assessment Project. Journal of Soil and Water Conservation 63(6):185A-197A.

Gassman, P.W., J.G. Arnold, R. Srinivasan, and M. Reyes. 2010. The worldwide use of the SWAT Model: Technological drivers, networking impacts, and simulation trends. In Proceedings of the Watershed Technology Conference, February 21-24. Costa Rica: American Society of Agricultural and Biological Engineers, Earth University.

Grafton, R.Q. 2005. Evaluation of Round One of Market Based Instrument Pilot Program. The Australian National University, Asian Pacific School of Economics and Government.

Grantham, H.S., M. Bode, E. McDonald-Madden, E.T. Game, A.T. Knight, and H.P. Possingham. 2010. Frontiers in Ecology and the Environment 8(8): 431-437.

Groffman, P., P. Capel, K. Riitters, and W.Yang. 2007. Ecosystem Services in Agricultural Landscapes. In Managing Agricultural Landscapes for Environmental Quality: Building the Science Base. Ankeny, IA: Soil and Water Conservation Society.

Kirwin, B., R. Lubowski, and M. Roberts. 2005. How cost-effective are land retirement auctions? Estimating the difference between payments and willingness to accept in the Conservation Reserve Program. American Journal of Agricultural Economics 87:1239-1247.

Lawler, J.J., J.E. Aukema, J.B. Grant, B.S. Halpern, P. Kareiva, C.R. Nelson, K. Ohleth, J.D. Olden, M.A. Schlaepfer, B.R. Silliman, and P. Zaradic. 2006. Conservation science: a 20-year report card. Frontiers in Ecology and the Environment 4:473-480.

Lerner, J., and J.Tirole. 2001. The open source movement: Key research questions. Europen Economic Review 45: 819-826.

Manale, A.P. 2008. Steering conservation's course using adaptive management. Journal of Soil and Water Conservation 63(6):183A-184A.

Maresch, W., M. Walbridge, and D. Kugler. 2008. Enhancing conservation on agricultural landscapes: A new direction for the Conservation Effects Assessment Project. Journal of Soil and Water Conservation 63(6):198A-203A.

Nelson, B. 2009. Data sharing: Empty archives. Nature 461(7261): 160-163.

Parr, C.S, and M. P. Cummings. 2005. Data sharing in ecology and evolution. Trends in Ecology \& Evolution 20(7):362-363.

Pullin, A.S, and Salafsky, N. 2010. Save the Whales? Save the Rainforest? Save the Data! Conservation Biology 24(4):915-917.

Reyers, B., D.J. Roux, R.M. Cowling, A.E. Ginsburg, J.L. Nel, and P.O. Farrell. 2010. Conservation planning as a transdisciplinary process. Conservation Biology 24(4):957-965.

Tallis, H., Y. Wang, B. Fu, B. Zhu, W. Zhu, M. Chen, C. Tam, and G. Daily 2010. The Natural Capital Project. Bulletin of the British Ecological Society 41(1):10-13.

Turner, R.K., and G.C. Daily. 2008. The ecosystem services framework and natural capital conservation. Environ Resource Econ 39(2):25-35.

Velterop, J. 2003. Should scholarly societies embrace open access (or is it the kiss of death)? Learned Publishing 16:167-169.

Yang, W., A.N. Rousseau, and P. Boxall. 2007. An integrated economic-hydrologic modeling framework for the watershed evaluation of beneficial management practices. Journal of Soil and Water Conservation 62(6):423-432. 